\title{
Pro-Inflammatory Role of AQP4 in Mice Subjected to Intrastriatal Injections of the Parkinsonogenic Toxin MPP+
}

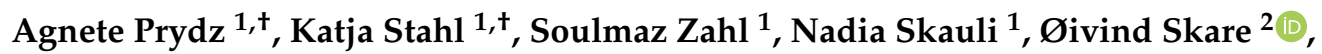 \\ Ole Petter Ottersen ${ }^{3}$ and Mahmood Amiry-Moghaddam ${ }^{1, * \mathbb{D}}$ \\ 1 Laboratory of Molecular Neuroscience, Division of Anatomy, Department of Molecular Medicine, \\ Institute of Basic Medical Sciences, University of Oslo, P.O. Box 1105, Blindern, 0317 Oslo, Norway; \\ agnpry@gmail.com (A.P.); katja.stahl@gmail.com (K.S.); soulmaz.r@gmail.com (S.Z.); \\ nadia.skauli@medisin.uio.no (N.S.) \\ 2 Department of Occupational Medicine and Epidemiology, National Institute of Occupational Health, \\ Gydas vei 8, 0363 Oslo, Norway; Oivind.Skare@stami.no \\ 3 President's Office, Karolinska Institutet, Nobels väg 6, 17177 Stockholm, Sweden; ole.petter.ottersen@ki.se \\ * Correspondence: mahmo@medisin.uio.no; Tel.: +47-91742177 \\ + These authors have contributed equally.
}

Received: 14 October 2020; Accepted: 2 November 2020; Published: 5 November 2020

\begin{abstract}
Aquaporin-4 (AQP4) is critically involved in brain water and volume homeostasis and has been implicated in a wide range of pathological conditions. Notably, evidence has been accrued to suggest that AQP4 plays a proinflammatory role by promoting release of astrocytic cytokines that activate microglia and other astrocytes. Neuroinflammation is a hallmark of Parkinson's disease (PD), and we have previously shown that astrocytes in substantia nigra (SN) are enriched in AQP4 relative to cortical astrocytes, and that their complement of AQP4 is further increased following treatment with the parkinsonogenic toxin MPTP (1-methyl-4-phenyl-1,2,3,6-tetrahydropyridine). Here, we investigated the effect of Aqp4 deletion on microglial activation in mice subjected to unilateral intrastriatal injection of 1-methyl-4-phenylpyridinium (MPP+, the toxic metabolite of MPTP). Our results show that MPP+ injections lead to a pronounced increase in the expression level of microglial activating genes in the ventral mesencephalon of wild type (WT) mice, but not Aqp $4^{-/}$mice. We also show, in WT mice, that MPP+ injections cause an upregulation of nigral AQP4 and swelling of astrocytic endfeet. These findings are consistent with the idea that AQP4 plays a pro-inflammatory role in Parkinson's disease, secondary to the dysregulation of astrocytic volume homeostasis.
\end{abstract}

Keywords: AQP4; Parkinson's disease; MPP+; astrocyte; microglia; neuroinflammation

\section{Introduction}

Of the 13 mammalian aquaporins (AQP) that have been discovered to date, three are expressed and functional in brain tissue [1]. One of these (AQP1) shows a very restricted expression, limited to the choroid plexus, while the other two (AQP4 and AQP9) are found in many brain regions, including the SN [2,3]. Other AQPs, including AQP2, 3, 5, 6 and 8, have been reported to be expressed in the brain, but so far only at the mRNA level [4].

AQP4 is by far the most prevalent aquaporin in brain-being expressed across all brain regions-and is particularly abundant at the brain-blood interface as a major component of the molecular assembly in perivascular astrocytic endfeet [5-7]. AQP9 is more weakly expressed, but with 
a preponderance in the mesencephalon [3]. Thus, both AQP4 and AQP9 are relevant in the context of Parkinson's disease.

AQP9 has a broad substrate profile and has been shown to mediate transport of parkinsonogenic compounds like arsenite and 1-methyl-4-phenylpyridinium (MPP+) [8,9]. In our previous study, we showed that the targeted deletion of $\mathrm{AQP} 9$ protects against $\mathrm{MPP}+$ induced degeneration of nigral neurons [8]. Based on this finding, we hypothesized that AQP9 could be parkinsonogenic by acting as an influx route of compounds that are toxic to nigral dopaminergic neurons.

Unlike AQP9, AQP4 is strikingly selective for water, due to the dimensional constraint and configuration of the channel pore, and plays an important role in brain water homeostasis and dyshomeostasis, including brain edema [10-13]. However, evidence has accrued to show that AQP4 is engaged in a host of brain functions and dysfunctions that are only indirectly coupled to or even independent of water transport $[7,14]$.

The list of neurological conditions in which AQP4 might play a pathophysiological role includes epilepsy [15,16] and neurodegenerative diseases, such as Alzheimer's disease (AD) [17-20], amyotrophic lateral sclerosis (ALS) [21,22], Huntington's disease (HD) [23] and spongiform encephalopathy (SE) [24]. Studies have also highlighted possible links between AQP4 and infectious and neuroinflammatory diseases, most notably meningitis [25], malaria [26] and neuromyelitis optica (NMO) [27].

Several neurological conditions-including epilepsy and a number of neurodegenerative diseases-also show hallmarks of neuroinflammation [28,29]. This is also true of Parkinson's disease (PD) [30]. Here, we use an animal model to explore our hypothesis that AQP4 could have a proinflammatory impact in PD. If so, this would further expand the number of roles attributed to AQP4 in neurological conditions.

The present work was inspired by study of Li et al. [31], which provided evidence of a proinflammatory role of AQP4 both in a mouse model of experimental autoimmune encephalopathy (EAE) and in an in vitro model. In both experimental approaches, mice or murine cell cultures with targeted deletion of AQP4 showed lower inflammation scores than wild type (WT) mice used as controls. The in vitro model showed that lipopolysaccharide (LPS) induced release of the cytokines TNF- $\alpha$ and IL-6 from astrocytes in an AQP4-dependent manner, possibly as a consequence of astrocytic swelling. These cytokines are known to activate cerebral microglia during neuroinflammation [32,33].

The goal of the present study was twofold. First, we set out to investigate whether intrastriatal injections of 1-methyl-4-phenylpyridinium (MPP+) - a mouse model of PD developed in our laboratory-upregulate expression of genes involved in microglial activation. Second, if such an effect could be demonstrated, we asked whether it is amplified by targeted deletion of AQP4. An answer in the affirmative would encourage further studies to resolve whether AQP4 serves a proinflammatory role in PD.

The timelines of this study is highlighted by recent investigations on AQP4 in brain. Notably, we have shown that nigral astrocytes are enriched in AQP4 relative to cortical astrocytes, and that their complement of AQP4 is further increased following treatment with MPTP (1-methyl-4-phenyl-1,2,3,6-tetrahydropyridine) [34]. MPP+—-the parkinsonogenic drug used in the present study - is the active metabolite of MPTP [35]. Further, imaging studies have revealed abnormal accumulation of water in mesencephala of patients with advanced PD [36].

Here, we demonstrate that MPP+ injections lead to an increase in microglial activation in the ventral mesencephalon, and that this increase is curbed by deletion of Aqp4. We also show, in WT mice, that MPP+ injections cause an upregulation of nigral AQP4 and swelling of astrocytic endfeet. These findings are consistent with the idea that upregulation of AQP4 plays a pro-inflammatory role in Parkinson's disease — possibly secondary to dysregulation of astrocytic volume homeostasis. 


\section{Materials and Methods}

\subsection{Animals}

Mixed gender and adult WT C57BL/6J mice (Jackson Laboratories, Boulder, CO, USA) bred in the local animal facility $(n=20)$ and constitutive $A q p 4^{-/-}$mice backcrossed for more than 10 generations on C57BL/6J background $(n=22)$ were used in this study. Aqp4 $4^{-1-}$ mice, generated as described by Thrane et al. [37], carry a mutated Aqp4 gene where exon 1-3 is replaced by a flippase recognition target (FRT)-neomycin-FRT-LoxP-validated cassette inserted downstream of exon 3, and a LoxP site inserted upstream of exon 1, thus, avoiding any expression of putative splice variants. Both experimental groups $\left(A q p 4^{-/-}\right.$and WT controls) were bred and kept at the local animal facility under the same conditions. For control purposes, we also purchased WT mice with the C57BL/6J genetic background from The Jackson Laboratory $(n=12)$. These animals had to be discarded as controls, as they differed from our internal controls (WT mice bred in the local facility) in regard to cell counts and their response to MPP+ (Supplementary Figure S1). The difference between these two cohorts of presumptive genetically identical animals is potentially interesting and will be the subject of further studies. Experimental protocols were approved by The Norwegian Animal Research Authority (NARA) with license number FOTS 4012 and carried out in accordance with the European Directive 2010/63/EU.

\subsection{Stereotaxic Surgery and Injection of MPP+}

The procedure was carried out as previously described [8]. In short, the animals were anesthetized with zoletil mixture (Zoletil Forte $(250 \mathrm{mg} / \mathrm{mL})$, Rompun $(20 \mathrm{mg} / \mathrm{mL})$ and Fentanyl $(50 \mu \mathrm{g} / \mathrm{mL})$; $0.1 \mathrm{~mL} / 10 \mathrm{~g}$; intraperitoneally) prior to fixing the head to a stereotaxic frame (TSE Systems, Bad Homburg, Germany). A total of $7.5 \mu \mathrm{g} \mathrm{MPP+} \mathrm{(Sigma-Aldrich,} \mathrm{St.} \mathrm{Louis,} \mathrm{MO,} \mathrm{USA)} \mathrm{dissolved} \mathrm{in} 1 \mu \mathrm{L}$ of $0.9 \%$ saline, or $1 \mu \mathrm{L}$ of $0.9 \%$ saline alone, was injected into the striatum $+0.6 \mathrm{~mm}$ anterior to bregma, $+2.2 \mathrm{~mm}$ laterally and $-3.2 \mathrm{~mm}$ ventrally [38] at $12 \mu \mathrm{L} / \mathrm{hr}$, using a syringe pump (Kd Scientific, Holliston, MA, USA) Body temperature was maintained at $36.5 \pm 0.5^{\circ} \mathrm{C}$ by a heating pad (PanLab, Barcelona, Spain), and the eyes were covered with Vaseline during the procedure.

\subsection{Post-Operative Animal Care}

At $24 \mathrm{~h}$ post-surgery, all animals were put on a heating pad overnight and were treated with Rimadyl ( $0.1 \mathrm{~mL} / 10 \mathrm{~g}$; s.c. every $12 \mathrm{~h})$ to prevent pain, and a mixture of $0.9 \%$ saline and $0.9 \%$ sucrose (s.c. every $24 \mathrm{~h}$ ) to restore water and energy balance. The animals were fed moisture pellets to improve food and water uptake. This treatment was continued for as long as needed, until the animals were sacrificed 7 days after surgery. The animals were scored daily for their weight and clinical appearance to evaluate the post-operative condition.

\subsection{Tissue Preparation for Light and Electron Microscopic Cytochemistry}

At 7 days post-surgery, the animals (WT; $n=20, A q p 4^{-1-} ; n=22$ ) were deeply anesthetized with zoletil mixture $(0.2 \mathrm{~mL} / 10 \mathrm{~g}$; i.p.), then euthanized by intra-cardial perfusion fixation with $2 \%$ ice cold dextran, followed by $15 \mathrm{~min}$ of $4 \%$ formaldehyde (FA), freshly depolymerized from paraformaldehyde (PFA), dissolved in $0.1 \mathrm{M}$ phosphate buffer (PB) for light microscopic cytochemistry, or $4 \%$ FA and $0.1 \%$ glutaraldehyde in 0.1 M PB for electron microscopic cytochemistry (all from Sigma-Aldrich). Brains were dissected out and post-fixed for $24 \mathrm{~h}$ in the fixation solution.

\subsection{Immunocytochemistry}

The tissue used for light microscopic cytochemistry was cryo-protected by sequential immersions in $10 \%, 20 \%$ and $30 \%$ sucrose solutions. The midbrain was then isolated and sectioned into coronal sections of $40 \mu \mathrm{m}$ on a HM 450 freeze microtome (Microm, Walldorf, Germany). From each animal, 10 sections were systematically selected for further immunohistochemical analyses (immunofluorescence; 
WT $(n=3)$, Aqp $^{-/-}(n=3)$ and stereological analysis; WT $(n=7)$, Aqp $^{-/-}(n=9)$, with a slice interval of $120 \mu \mathrm{m}$, covering the entire substantia nigra pars compacta (SNpc), from Bregma -2.70 to -3.80 [38]. Immunocytochemistry for stereological quantifications has been previously described [8]. In brief, free-floating sections were blocked and permeabilized before incubation in primary antibody (Table 1) overnight, followed by incubation with secondary and tertiary antibody. Finally, sections were incubated with 3,3'-diaminobenzidine (DAB; Sigma-Aldrich) dissolved in $0.1 \mathrm{M}$ PBS, then treated with a DAB-solution containing $0.03 \% \mathrm{H}_{2} \mathrm{O}_{2}$ (Applichem, Darmstadt, Germany), before washing and mounting with glycerin-gelatin.

For immunofluorescence and confocal imaging, free floating sections were blocked, permeabilized and incubated with primary antibody (Table 1), prior to incubation with species-specific secondary antibodies prior to mounting. Images were collected with a LSM 510 META Confocal Microscope (Zeiss, Jena, Germany) using a 40× oil objective. 4', 6 -diamidino-2-fenylindol (DAPI) fluorescence was captured at $405 \mathrm{~nm}$, Alexa 488 at $510 \mathrm{~nm}, \mathrm{Cy} 3$ at $568 \mathrm{~nm}$ and Cy5 at $670 \mathrm{~nm}$.

Table 1. Primary secondary and tertiary antibodies for immunocytochemistry and -fluorescence.

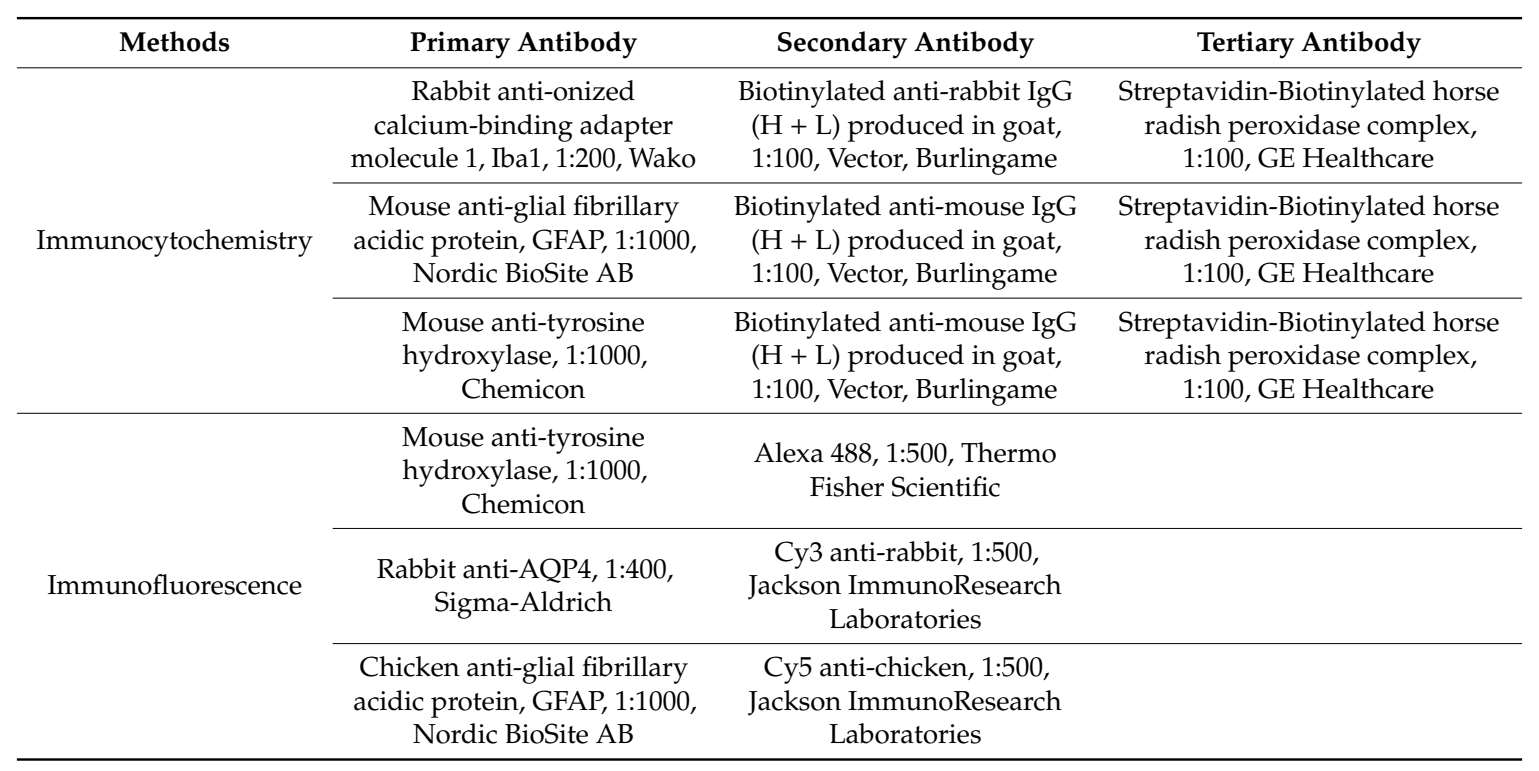

\subsection{Stereological Quantifications of Dopaminergic Density in the Midbrain}

Stereological quantifications of dopaminergic cells in midbrain subregions was performed bilaterally in WT and Aqp $4^{-/-}$mice injected with MPP+ or saline. The investigator was blinded to genotype and treatment. The procedure has been described in detail [8].

\subsection{Electron Microscopy}

Tissue blocks $<1 \mathrm{~mm}^{3}$ of SNpc from both the ipsilateral and the contralateral hemisphere of WT and Aqp $4^{-/-}$mice were dissected out, cryoprotected in glycerol and quickly frozen in liquid propane $\left(-170{ }^{\circ} \mathrm{C}\right)$. The tissue was then subjected to freeze substitution [39], embedded in Lowicryl HM20 Resin (Lowy, Waldkraiburg, Germany) at $-30{ }^{\circ} \mathrm{C}$ and polymerized by UV light. Ultrathin sections of 90-100 nm were cut from the blocks using an ultramicrotome (Leica EM UC6, Vienna, Austria) and transferred to mesh grids [40]. Each section was contrasted with uranyl acetate and lead citrate for $1.5 \mathrm{~min}$ and rinsed in $\mathrm{ddH}_{2} \mathrm{O}$ in-between. The sections were examined using an electron microscope (Tecnai 12, FEI Company, Eindhoven, The Netherlands). 


\subsection{Electron Microscopic Analysis}

For the quantification of endfoot width, as an indicator for swelling, 25 electron micrographs of randomly selected capillaries from SN of WT $(n=4)$ and Aqp4 $4^{-/-}$mice $(n=4)$ were obtained from each section at 26,500× magnification. Endfoot width was assessed by calculating endfoot area per unit length of adluminal membrane using the software program ImageJ (U. S. National Institutes of Health, Bethesda, MD, USA). The analyzer was blind to genotype and area.

\subsection{RNA Isolation and Quantitative Real Time qPCR Analysis}

At 7 days post-surgery, the animals injected with MPP+ (WT $(n=6), A q p 4^{-/-}(n=5)$ or saline WT $\left.(n=3), A q p 4^{-1-}(n=3)\right)$ were decapitated under isofluorane (Baxter, Deerfield, IL, USA) anesthesia and the brains were dissected out. The brains were cut along the midsagittal line to separate the injected and control hemispheres. The midbrain and striatum were dissected out from both hemispheres, snap frozen and stored at $-80{ }^{\circ} \mathrm{C}$ until analysis. The total RNA was isolated from the regional brain samples using the RNeasy Plus Mini Kit (QIAGEN, Hilden, Germany). The RNA concentration and integrity were determined using the NanoDrop 2000c spectrophotometer (Thermo Scientific, Oslo, Norway) and agarose gel electrophoresis. The cDNA was synthesized using GoScript Reverse Transcription System (Promega, Madison, WI, USA) using Oligo (dT)15. The gene expression was evaluated by using the qPCR absolute quantification. The qPCR was performed in a total volume of $20 \mu \mathrm{L}$, containing the Power SYBR Green PCR Master Mix (Applied Biosystems, Oslo, Norway), forward and reverse primers $(10 \mu \mathrm{M})$, and $10 \mathrm{ng}$ of total cDNA per reaction. Thermal cycling was performed on the StepOnePlus system (Applied Biosystems) with the following conditions: $95^{\circ} \mathrm{C}$ for $10 \mathrm{~min}$, followed by 40 cycles at $95^{\circ} \mathrm{C}$ for $15 \mathrm{~s}$ and $60{ }^{\circ} \mathrm{C}$ for $1 \mathrm{~min}$ and at the end the melting curve step. No reverse transcriptase (NRT) and no template control (NTC) negative controls were included in the study. Using the NormFinder software (Aarhus, Denmark), the expression variation of $A c t b$, H2afz, Pgk1 and $U b c$ as endogenous reference genes were evaluated. $U b c$ was selected as the most stable endogenous control for normalization across groups and regions with a stability value of 0.184 . One-way ANOVA with Bonferroni post hoc test was used for statistical analysis of the data. The data are presented as mean $\pm 2 \mathrm{SE}$, and $p<0.05$ was considered as significant. A list of the primer pairs used in the experiment is shown in Table 2.

Table 2. Primer pairs.

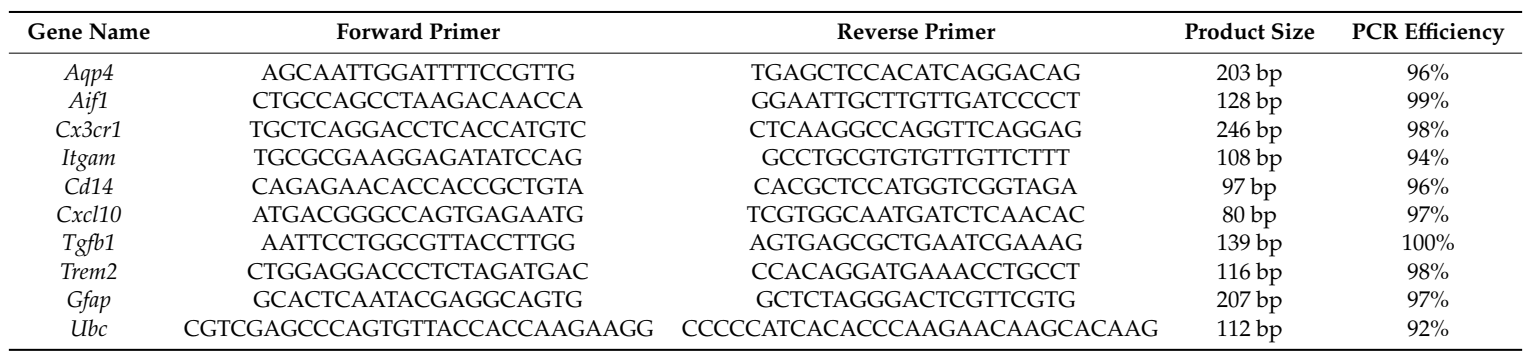

\section{Results}

\subsection{Survival Rate and Clinical Appearance Post-Surgery}

All animals were scored daily for their clinical appearance, including the parameters weight loss, inactivity, appearance and reaction patterns, giving a total score ranging from 0-12. Animals reaching a score of 10 or above were considered severely affected by the toxin and were euthanized, due to ethical concerns. Among the total number of animals treated with MPP+ $(n=32)$, five animals died or were euthanized. Among those animals, three animals were WTs, while two animals were Aqp $4^{-1-}$. There was no difference in behavioral assessments between WT and Aqp $4^{-/-}$mice. 


\subsection{Unilateral Intrastriatal Injections of MPP+ Lead to Astrogliosis and Microgliosis in the Ipsilateral SN}

Astrogliosis and microgliosis have been demonstrated in the ventral midbrain of many animal models of PD, including systemic treatment with MPTP [34,41]. We investigated if unilateral intrastriatal $\mathrm{MPP}+$ injections induce astrogliosis and microgliosis in the ventral midbrain. Light microscopic immunohistochemistry of midbrain sections of animals subjected to unilateral intrastriatal MPP+ injections showed stronger glial fibrillary acidic protein (GFAP) and ionized calcium-binding adapter molecule 1 (Iba1) staining in the injected hemisphere, compared to the control hemisphere (Figure $1 \mathrm{~A}-\mathrm{H}$ ). WT and Aqp $4^{-/}$animals did not differ in this regard. In both groups of animals, GFAP-positive astrocytes were most abundant in a distinct area corresponding to the $\mathrm{SN}$ of the injected hemisphere (Figure 1B,D). In both genotypes, the SN of the injected hemispheres showed strong immunostaining for

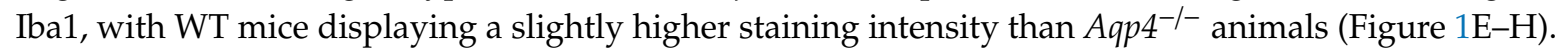
Microglia stained for Iba1 exhibited enlarged cell bodies and chubby processes (Figure 1F,H) indicative of a microglial reactive state [42].
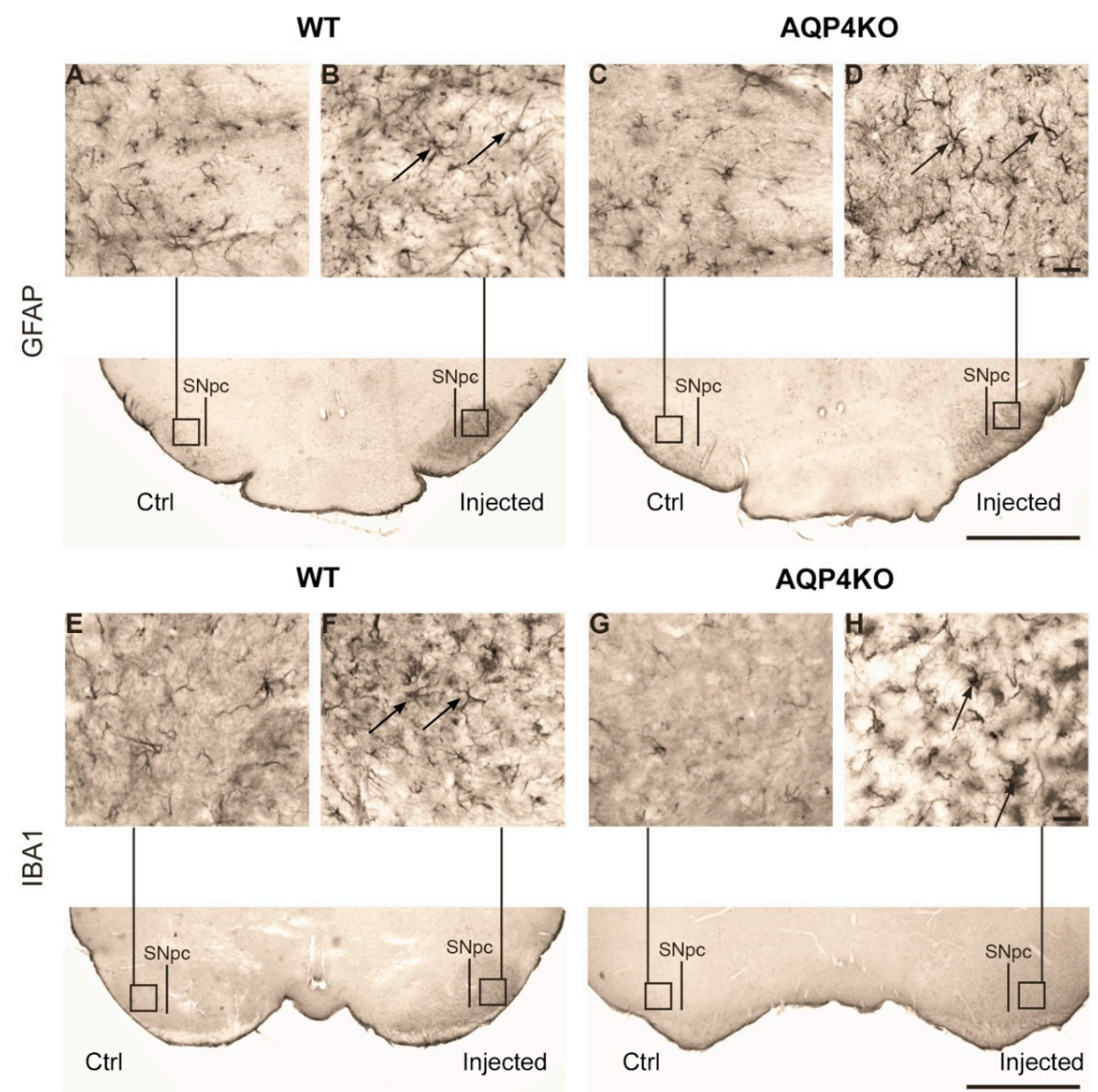

Figure 1. Increased expression of glial fibrillary acidic protein (GFAP) and (ionized calcium-binding adapter molecule 1) Iba1 in substantia nigra (SN) following treatment with MPP+. Representative micrographs showing midbrain sections immunostained with antibodies to the astrocyte marker GFAP upper panel (A-D) or the microglial marker Iba1 lower panel (E-H). Unilateral injection of 1-methyl-4-phenylpyridinium (MPP+) in the striatum resulted in increased expression of GFAP (arrows B,D) in the ipsilateral substantia nigra pars compacta (SNpc) (injected, B,D) compared to the contralateral hemisphere (Ctrl, A,C) in wild type (WT) $(\mathbf{A}, \mathbf{B})$ as well as in Aqp4 $4^{-/}$animals (C,D). An increased expression of Iba1 (arrow $\mathbf{H}$ ) is also visible in the ipsilateral SNpc $(\mathbf{F})$, compared to the contralateral hemisphere (E) in WT, as well as in Aqp $4^{-/-}$animals, respectively, $(\mathbf{H}, \mathbf{G})$. Iba1 showed a slightly higher staining intensity in WT compared to Aqp $4^{-/-}$animals (lower panel, compared the area around SNpc in the injected hemispheres). Scale bar: $1000 \mu \mathrm{m}$; inset: $20 \mu \mathrm{m}$. 


\subsection{Unilateral Intrastriatal MPP+ Injections Lead to a Strong Increase in the Transcript Levels of Microglial} Activating Genes in Ipsilateral Midbrain of Wild Type but Not Aqp4 ${ }^{-/}$Mice

We performed quantitative real time PCR analysis on samples from midbrain of injected and control hemispheres of WT and Aqp $4^{-/-}$mice (Figure 2). Confirming the immunohistochemical data, our analysis showed increased expression level for Gfap in the midbrain of the MPP+ injected hemisphere compared to midbrain of the control hemisphere in both WT (control: $1035 \pm 134$ injected: $3487 \pm 542 p<0.001$ ) and Aqp $4^{-/-}$mice (control: $753 \pm 448$, injected: $4182 \pm 1438 p<0.001$ ). There was no significant difference between the two genotypes. The expression level of the general microglial marker Iba1 (Aif1) was significantly increased in the injected hemisphere of both genotypes. Notably, the transcript levels of Aif 1 in the ipsilateral midbrain were significantly higher in WT than in Aqp $4^{-/-}$ mice (WT: $2217.4 \pm 242.2$ vs Aqp $4^{-/-}: 1295.3 \pm 220.8 p<0.001$ ).

To resolve whether AQP4 plays a pro-inflammatory role, we analyzed the expression levels of key genes coding for microglial membrane receptors known to be upregulated during inflammation. We specifically investigated the expression levels of $C d 14$, a key organizer of microglial inflammatory response [43]; Trem2, a receptor promoting microglial survival, proliferation and phagocytic activity [44]; Cx3cr1, a chemokine receptor involved in microglial inflammatory response [45,46]; and Itgam, the gene coding for the integrin receptor CD11b involved in microglial adhesion and migration [47]. In WT animals, our qPCR analysis revealed a several fold increase in the expression levels of each of these genes in midbrain samples ipsilateral to MPP+ injections. In Aqp $4^{-/-}$mice, in contrast, none of these genes differed significantly between injected and control hemispheres in regard to levels of expression (Figure 2).

We also analyzed the expression levels of the two cytokines, $T g f b 1$ and $C x c l 10$, previously shown to be upregulated in MPTP models of PD $[48,49]$. Under normal conditions in the midbrain, TGF- $\beta 1$ is mainly expressed by neurons, while under pathological conditions, it is, in addition, highly expressed in activated microglia [50], and its secretion leads to the upregulation of microglial CX3CR1 [51,52]. CXCL10 is expressed in and secreted by astrocytes and to some extent by microglia [53,54]. Earlier studies have shown that release of CXCL10 from astrocytes is involved in early microglial activation, initiating migration and inducing a pro-inflammatory phenotype [55]. Expression levels of both chemokines were strongly increased in the midbrain of the injected hemisphere of WT mice, compared to the control side (Tgfb1, control: $60.4 \pm 6$, injected: $202.9 \pm 41.4, p<0.001$; Cxcl10, control: $42.8 \pm 18.2$, injected: $1492.7 \pm 340, p<0.001)$. However, in the Aqp $4^{-/-}$midbrain samples, only the increase in the expression level of $C x c l 10$ reached significant levels (control: $83.9 \pm 37.8$, injected: $1128.6 \pm 342$, $p<0.001$ ), while $T g f b 1$ failed to increase significantly, following unilateral intrastriatal MPP+ injection (injected: $104.8+23.7$, control: $66.4+17.6, p>0.05$ ), indicating reduced microglial activation.

Quantitative real-time PCR analysis showed a significant increase in the expression levels of Gfap and Aif1 in the midbrain of MPP+ injected hemispheres in both the WT and Aqp $4^{-/-}$mice. The increase observed in the injected hemispheres of the WT mice was significantly higher for Aif 1 than the increase in the injected hemisphere of $A q p 4^{-/-}$mice $(p<0.01)$. In the case of Gfap, there was a significant increase in the transcript levels in the injected hemisphere compared to the control hemisphere of both genotypes $p<0.001$, with no significant difference between the genotypes.

Expression of $C d 14$ was increased from $70.2 \pm 9.2$ mRNA copies per ng RNA in the control midbrain to $174.5 \pm 26.4$ copies in the injected midbrain of the WT mice $(p<0.001)$, compared to $49.5 \pm 10.4$ in the control and $83.8 \pm 26$ in the injected hemispheres of the Aqp $4^{-/-}$mice $(p=1.0)$. The trend was similar for Trem 2 (WT control: $76.4 \pm 13.6$, WT injected: $568.3 \pm 116, p<0.001$ vs Aqp $4^{-/-}$ control: $111.1 \pm 39.4$, Aqp $^{-/-}$injected: $222.0 \pm 64, p=1.0$ ) Cx3cr1 (WT control: $243.3 \pm 40.6$, WT injected: $743.9 \pm 171.6, p<0.001$ vs Aqp $4^{-/-}$control: $296.2 \pm 176.8$, Aqp $^{-/-}$injected: $315.7 \pm 169.2, p=1.0$ ),

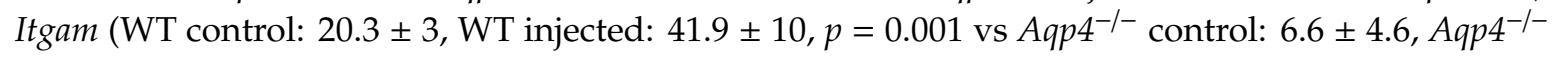
injected: $17.6 \pm 11.2, p>0.05$ ). The mRNA expression of Tgfb1 and Cxcl10, were significantly increased in the ipsilateral hemisphere of the WT animals compared to control hemisphere, and the increase was significantly higher than that observed in the Aqp $4^{-/-}$animals, at $p<0.05$ and $p<0.01$, respectively. 
In the Aqp $4^{-/-}$mice, the increase in the expression levels of $C x c l 10$ and not $T g f b 1$, reached significant levels in the midbrain ipsilateral to the MPP+ injection, compared to the control midbrain.
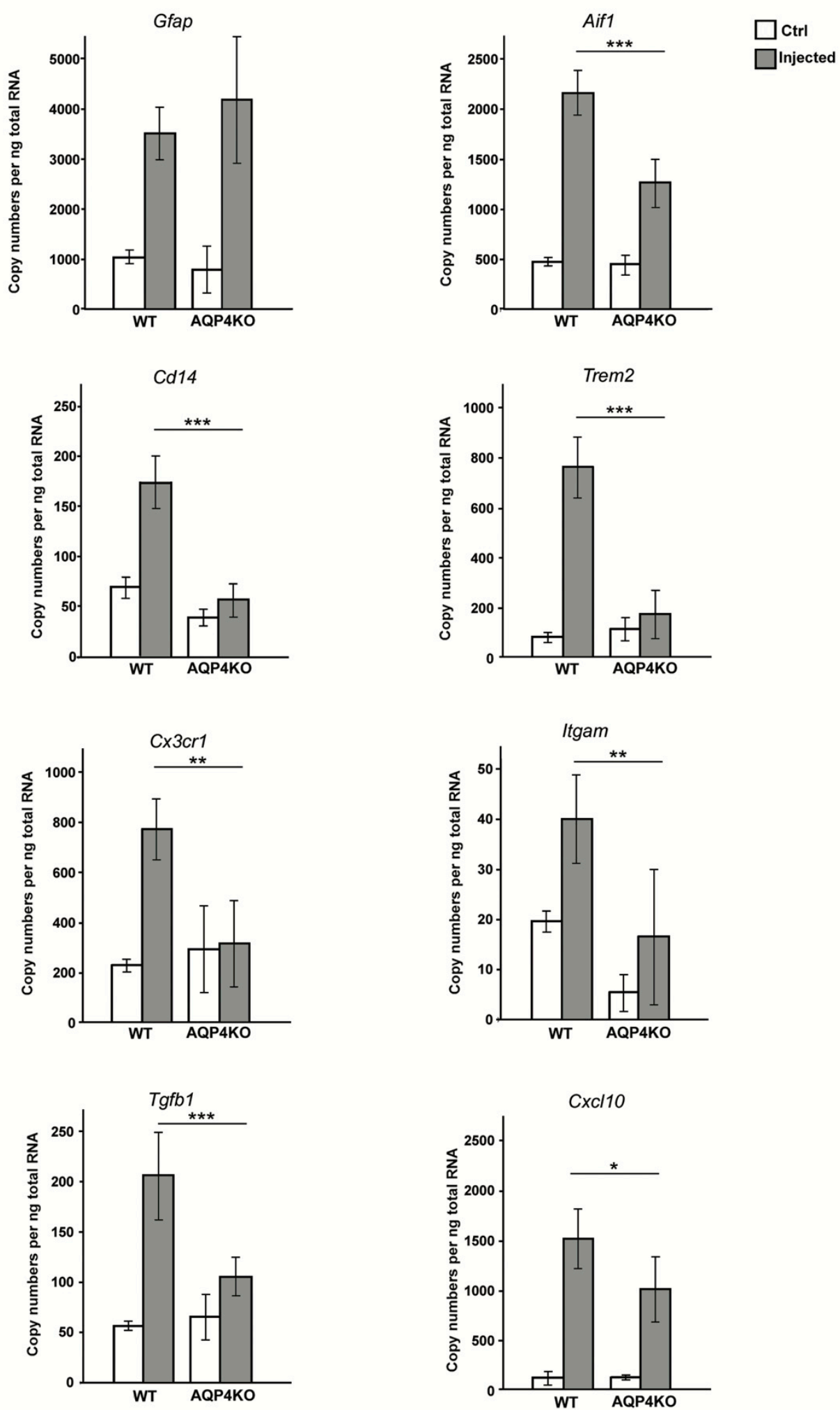

Figure 2. Increased mRNA levels of microglial activating genes in ipsilateral midbrain of WT but not Aqp $4^{-/-}$mice, following unilateral intrastriatal MPP+ injections. Bars are mean \pm 2 SEM. ${ }^{*} p<0.05$, ** $p<0.01,{ }^{* * *} p<0.001$ 


\subsection{Expression of $A Q P 4$ in $S N$ after MPP+ Injections}

We have previously shown that systemic MPTP treatment causes an upregulation of AQP4 expression in SN [34]. Here, we investigated whether unilateral intrastriatal injections of MPP+ have a similar effect. Our immunofluorescence analysis revealed an increased expression of AQP4 ipsilateral to, but not contralateral to MPP+ injections, particularly around larger vessels and in the neuropil of the SN (Figure 3A,B). Ipsilateral and contralateral SN showed no difference in AQP4 immunofluorescence labeling intensity when MPP+ injections were replaced by unilateral intrastriatal injections of saline (Figure 3C,D).

Quantitative real time PCR analysis showed that Aqp4 expression in the midbrain was significantly increased in the hemisphere treated with $\mathrm{MPP}+$, as compared to the contralateral control hemisphere and saline controls (Figure 3E). The transcript levels of Aqp4 mRNA in hemispheres treated with MPP+ was $4976 \pm 1110$ mRNA copies per ng RNA, compared with $1397 \pm 124.4$ in the control hemisphere $(p<0.001)$.
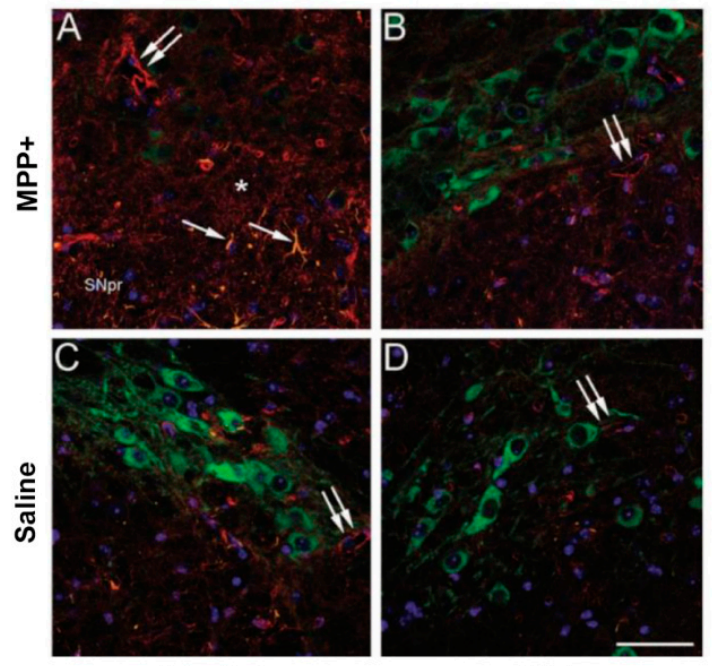

Injected

Ctrl

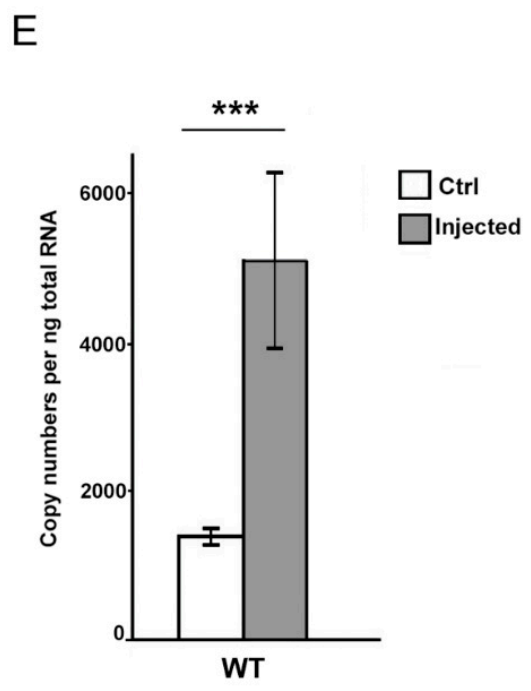

Figure 3. Increased expression of Aquaporin-4 (AQP4) protein and mRNA in the substantia nigra following treatment with $\mathrm{MPP}+(\mathbf{A}-\mathbf{D})$. Unilateral injection of $\mathrm{MPP}+$ in the striatum results in loss of TH-positive cells (green) in the ipsilateral SNpc (A, injected) compared to the contralateral SNpc (B, ctrl) and animals receiving unilateral injections of saline (C,D). Strong upregulation of AQP4 (red) is further observed in the ipsilateral SN, particularly around larger vessels (double arrows) (A) compared to larger vessels in the control hemisphere (B) and saline controls (C,D). Increased AQP4 labeling is also evident in non-endfeet membranes of the neuropil (asterisk) following treatment with $\mathrm{MPP}+(\mathrm{A})$. The toxin also induced upregulation of GFAP (orange) in the ipsilateral hemisphere (single arrow), (A). The injected hemisphere showed significantly fewer TH-positive cells (green, A) compared to the control hemisphere (B). Increased levels of Aqp4 mRNA following treatment with MPP+ (E). Quantitative real-time PCR analysis showed more than two-fold higher expression of Aqp4 mRNA in midbrain samples ipsilateral to the MPP+ injection compared to midbrain samples of the control hemisphere (ctrl). Bars are mean \pm 2 SEM. ${ }^{* * *} p<0.001$. Scale bar: $50 \mu \mathrm{m}$.

\subsection{Electron Microscopic Analysis of Endfoot Width}

EM analysis showed an increased width of perivascular astrocyte endfeet in WT and Aqp4 $4^{-1-}$ mice injected with MPP+ compared with saline controls (Figure 4). Endfoot width was larger in MPP+ injected WT mice $(1.28 \mu \mathrm{m} \pm 0.28)$ than in MPP+ injected Aqp $4^{-/-}$animals $(0.8 \mu \mathrm{m} \pm 0.2 ; p<0.01)$. Additionally, after saline injections did the two genotypes differ in regard to endfoot width (Figure 4). 


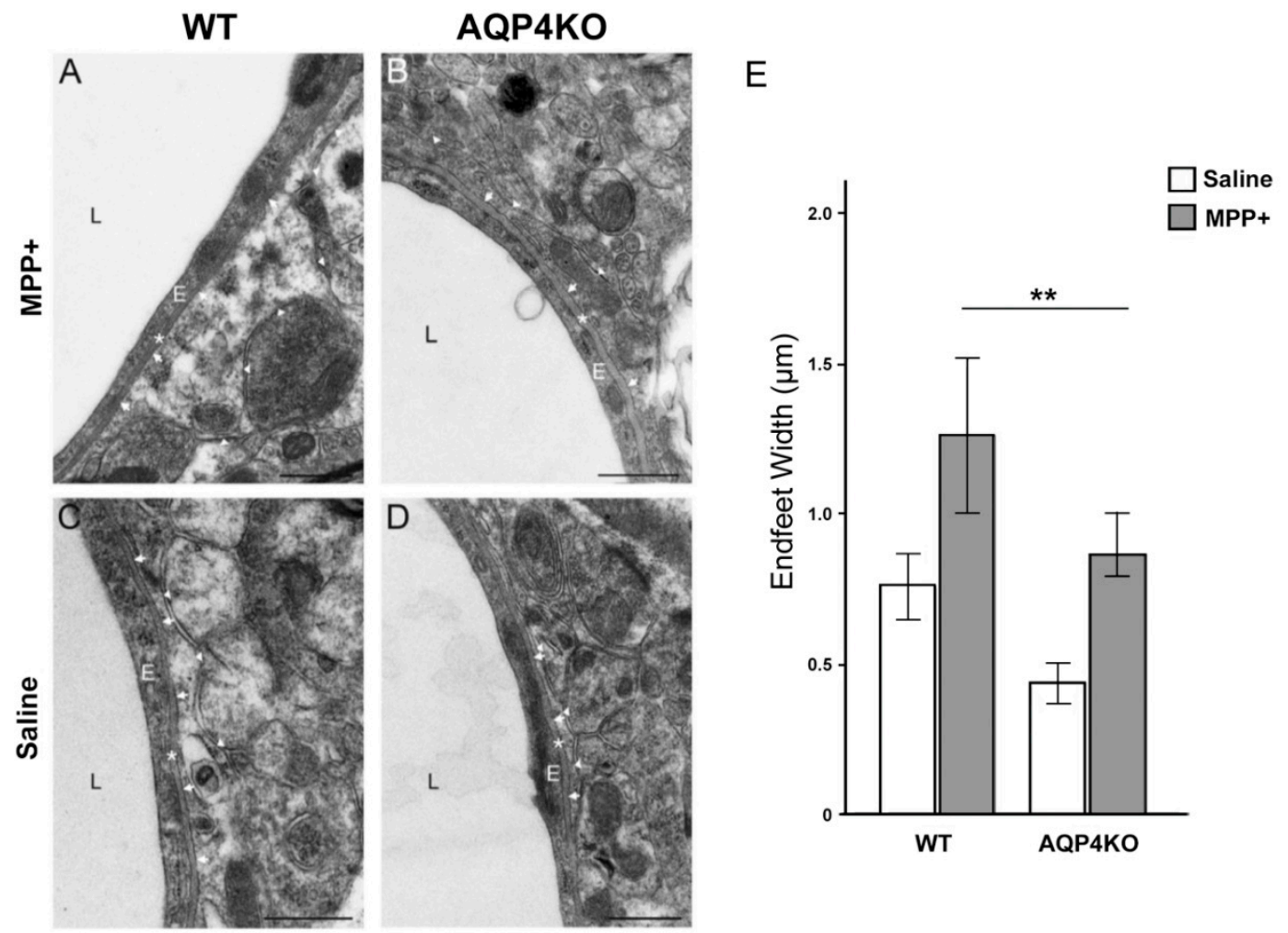

Figure 4. Perivascular endfoot width following treatment of MPP+ and saline. Electron micrographs of perivascular astrocytic endfeet in animals exposed to $\mathrm{MPP}+$ treatment $(\mathbf{A}, \mathbf{B})$ and saline controls (C,D). Arrows mark the membrane domains of the astrocytic endfoot facing endothelial basal lamina, arrowheads mark membrane facing neuropil, thus, identifying the astrocyte endfoot. Asterisks marks basal lamina between the endothelial cell and astrocyte endfoot. The statistical analysis of the perivascular astrocytic endfoot width in SNpc of MPP+ injected hemispheres (E) showed a larger endfoot width in both genotypes, compared to the saline controls $(p<0.01)$. The endfoot width in the WT animals was larger compared to the Aqp $4^{-/-}$animals in both the MPP+ and saline injected hemispheres $(p<0.01)$. E, endothelial cell; L, capillary lumen. Bars are mean \pm 2 SEM. ${ }^{* *} p<0.01$. Scale bar: $500 \mathrm{~nm}$.

\subsection{Stereological Quantification of Dopaminergic Cell Density}

Dopaminergic cells (TH-ir cells) in the ipsi- (Figure 5A,C) and contralateral (Figure 5B,D) hemispheres of SNpc were quantified in $A q p 4^{-/-}$and WT animals subjected to unilateral intrastriatal injections of MPP+ or saline. The number of TH-ir cells in the MPP+ injected hemisphere was significantly higher in Aqp $4^{-/-}$mice than in WT, with average cell counts of respectively $1789 \pm 262$ and $1401 \pm 82(p<0.05$, Figure 5E).

In animals treated with saline, no difference in TH-ir cell counts was observed between genotypes or between the ipsi- and contralateral side within genotypes (Figure 5F).

TH-ir cell counts in ventral tegmental area (VTA) revealed no significant differences between ipsiand contralateral midbrain following unilateral MPP+ injections. Further, cell counts in VTA did not differ between WT and Aqp4 $4^{--}$mice after MPP+ injections, nor after injections of saline (Figure 5G). 
A

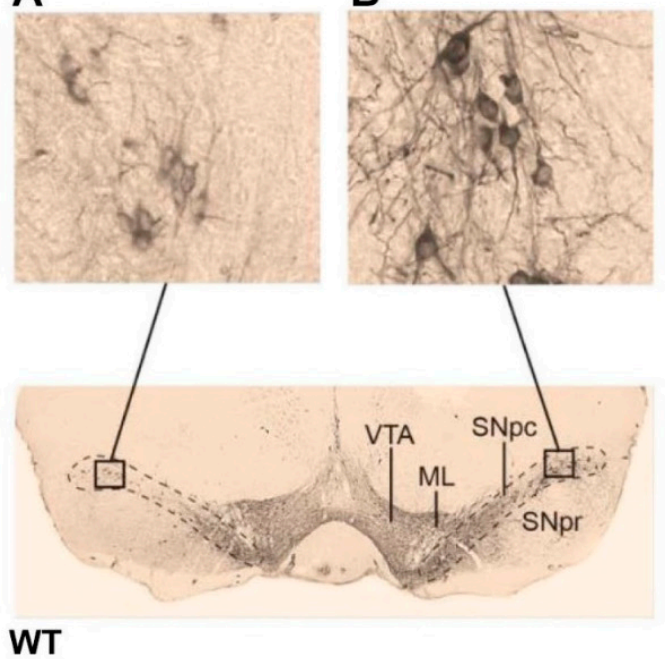

C

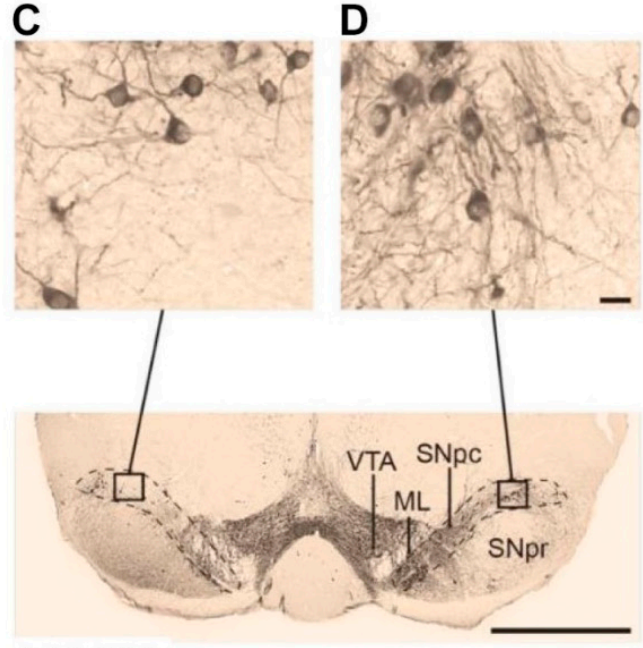

AQP4KO
E

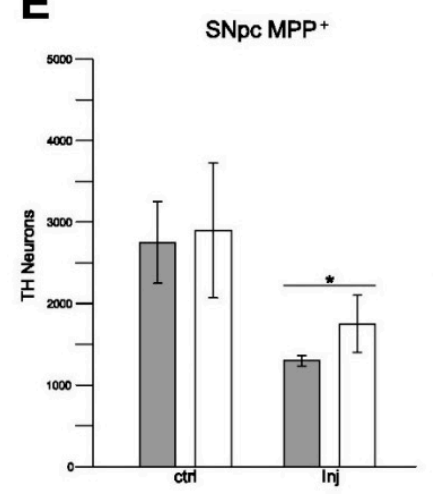

F

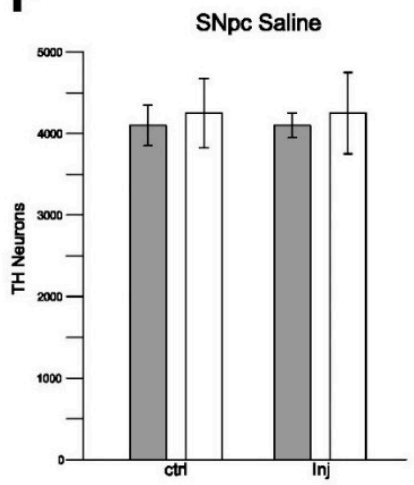

G

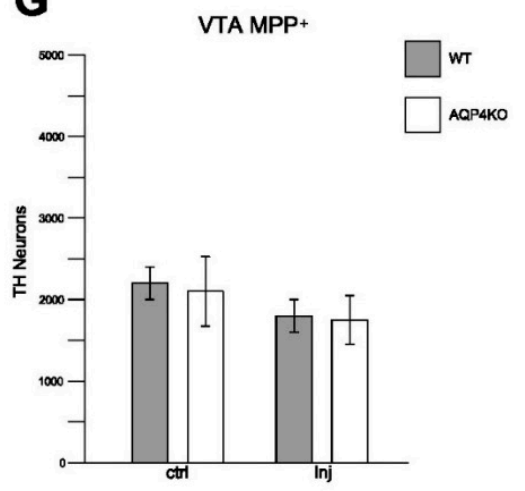

Figure 5. Dopaminergic neuronal cell count after unilateral treatment with $\mathrm{MPP}+$ or saline in the SNpc and ventral tegmental area (VTA) of $A q p 4^{-/-}$and WT animals. Following unilateral treatment with $\mathrm{MPP}+$, loss of TH-immunoreactive (TH-ir) cells is evident in the ipsilateral hemisphere $(\mathbf{A}, \mathbf{C})$ compared to the contralateral side (B,D) in both $A q p 4^{-/-}$and WT animals. In the SNpc, the average TH-ir cell count reduced from $2742 \pm 490$ in the control hemisphere to $1401 \pm 82$ in the injected hemisphere of the WT animals $(p<0.001)$ (E). In Aqp4 ${ }^{-/-}$animals, the average TH-ir cell count for the control and injected hemispheres were $2940 \pm 856$ and $1789 \pm 262$, respectively $(p=0.052)$. The number of TH-ir cells in the MPP+ injected hemisphere was significantly higher in Aqp $4^{-/-}$mice than in WT (E). Unilateral treatment with saline did not result in reduction in the dopaminergic cell count in the ipsilateral

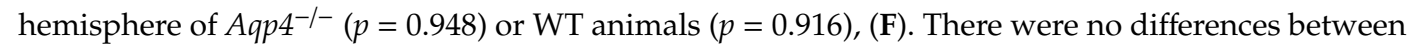
the injected hemispheres or the control hemispheres of the two genotypes, respectively $p=0.732$ and $p=0.693$ (F). In the VTA, no significant differences were observed in the cell count of TH-positive cells in the two hemispheres of the two genotypes, ( $p=0.607$ for Aqp $4^{-/-}$and $p=0215$ for WT, G). There were no differences between the genotypes in the injected side $(p=0.860)$ or the control sides $(p=0.864)(\mathbf{G})$. Bars are mean \pm 2 SEM. Scale bars: $1000 \mu \mathrm{m}$; inset: $20 \mu \mathrm{m}$. ${ }^{*} p<0.05$.

\section{Discussion}

The question explored in the present study is whether AQP4 - the most prevalent aquaporin in brain-is involved in the pathophysiology of PD, and if so-is it protective or does it exacerbate disease progression?

Recent studies in our laboratory and others have shown that AQP4 is more strongly expressed in nigral astrocytes than in astrocytes in cortex or hippocampus, and that its expression is further increased after MPTP injections in mice [34], and after 6-hydroxydopamin (6-OHDA) injections in 
rats [56]. It is also interesting to note that imaging studies have revealed abnormal accumulation of water in mesencephala of patients with advanced Parkinson's disease [36]. Further, several studies have pointed to a putative coupling between AQP4 and inflammation [31,57]. These findings prompted us to investigate whether AQP4 could be involved in neuroinflammatory processes relevant for the development of PD. We chose a model that was successfully used to identify a putative link between AQP9 and loss of dopaminergic neurons. Our results show that AQP4 deletion restrains MPP+ induced upregulation of genes involved in microglia activation. Specifically, compared with WT mice, mice with targeted deletion of Aqp4 revealed significantly lower expression of microglial genes known to be involved in microglial migration and phagocytosis.

Under pathological conditions, microglial activation is triggered by signal substances and inflammatory mediators released by peripheral immune cells, damaged neurons and astrocytes $[32,33,58]$. Of these cell types, only astrocytes are known to express AQP4. Thus, it is likely that the effects of Aqp4 deletion presently reported are mediated by astrocytes.

Neuroinflammation is a hallmark of PD and of animal models of PD [59]. Microglia have been shown to be the main actors in the neuroinflammatory process contributing to dopaminergic cell loss, and several lines of evidence indicate that reactive astrocytes play an essential role in microglia activation. Upon exposure to neuronal $\alpha$-synuclein, astrocytes express high levels of proinflammatory cytokines involved in migration and activation of microglia $[53,60]$. Moreover, the key role of astrocytes in MPTP-induced neuroinflammation and microglial activation was demonstrated in a recent study where astrocyte-specific deletion of inhibitor of nuclear factor kappa-B kinase subunit $\beta$ (IKK2), a central upstream activator of NF-kB, led to reduced neuroinflammation and microglial activation following MPTP treatment [61]. These findings are in line with the idea that astrocytes may sustain neuroinflammation in PD models.

While a proinflammatory role of AQP4 is consistent with the early study of Li et al. [23], the present findings are not easily reconciled with recent studies suggesting that AQP4 may play an immunosuppressive role in models of MPTP and LPS induced neuroinflammation [62,63]. The latter studies reported that Aqp4 $4^{--}$mice treated with MPTP or LPS revealed an increased microglial inflammatory response and a more pronounced loss of TH-neurons in the SN, compared with WT mice. The Aqp $4^{-/-}$mouse line used in these studies was found to have an impaired blood brain barrier, even in the absence of any experimental intervention [64]. A leaky blood brain barrier implies that the microenvironment of neurons and glia is perturbed and that neural cells are exposed to immune cells and molecules that are normally retained in blood. This makes results difficult to interpret. The Aqp $4^{-/-}$ mouse line used in the present study has an intact blood brain barrier [65]. It is worth noting that MPTP alone does not lead to a disruption of blood brain barrier function [66].

As to the mechanisms underlying the present findings, Li et al. found that release of inflammatory mediators such as interferon gamma (IFN $\gamma$ ) and IL-1 $\beta$ by astrocytes was coupled to AQP4-dependent astrocyte swelling [31]. We have previously shown that astrocytes release ATP, another activator of microglia, in an AQP4-dependent manner [37,67]. The exact mechanism of this AQP4-dependent ATP release is not known, but it could occur as part of the regulatory volume decrease where AQP4 and other AQPs have been shown to be involved $[68,69]$.

In the present study, we demonstrate that $A q p 4^{-/-}$mice subjected to MPP+ injections show less swelling of astrocytic endfeet than MPP+ injected WT mice. We conclude that the most salient explanation of our findings is that Aqp4 deletion curbs swelling induced release of compounds that normally cause microglial activation and inflammation.

Importantly, we show, in the current study, that astrocytic endfeet in SN are more swollen than endfeet in Aqp4 $4^{-/-}$mice both under basic conditions and after MPP+ exposure. The enrichment of AQP4 in nigral astrocytes and its further upregulation after toxin exposure may contribute to stronger inflammatory response and represent an additional factor contributing to the selective vulnerability of $\mathrm{SN}$ to toxins. Upregulation of AQP4 similar to that found here has been reported in several studies of chronic neurodegenerative diseases, including PD [34], AD [17,18,20,70], ALS [21,22] and SE [24], 
indicating that increased expression of AQP4 is a common feature of neurodegeneration. Interestingly the sensitivity to MPTP (and inflammatory response) is increased in aged mice [71], which express higher levels of AQP4 than younger mice [72].

The present study was designed to assess the effect of Aqp4 deletion on microglial activation in ventral mesencephalon, a process thought to occur upstream of cell degeneration. However, even at this early time point, the loss of dopaminergic neurons after MPP+ injections was less pronounced in Aqp $4^{-/-}$mice, compared with WT controls ( $38 \%$ vs $45 \%$ ). Our data are consistent with the findings by other groups showing that dopaminergic cell loss is lower in TLR4-deficient mice vs WT one week after treatment with MPTP (34\% vs 45\%) [73]. TLR4 is member of Toll-like receptor family that mediates microglial activation in neurodegenerative diseases, including PD [74].

\section{Conclusions}

It is well established that PD is associated with neuroinflammation through elevation of cytokines [75], some of which are released by reactive astrocytes $[53,60]$ and lead to activation of microglia [76].

This is the first study to show that Aqp4 deletion reduces microglial activation indicating that AQP4 plays a proinflammatory role in a model of PD. The mechanisms underlying this effect remain to be identified, but the most likely explanation is that AQP4 promotes swelling of astrocytes and hence swelling-induced release of ATP and other compounds that, in turn, activate nigral microglia. Taken together with previous studies, our data suggest that two of the three aquaporins that are functional in brain-i.e., AQP4 and AQP9-are implicated in PD, albeit in fundamentally different ways. While AQP9 may serve to facilitate toxin access [8], AQP4 is likely to exacerbate the effect of toxin exposure. We hypothesize that differences in AQP4 or AQP9 expression-related to age, environmental exposure or genetic factors-may affect vulnerability to PD. This hypothesis will be explored in future studies.

Supplementary Materials: The following are available online at http://www.mdpi.com/2073-4409/9/11/2418/s1, Figure S1: Stereological Quantification of Dopaminergic Cell Density comparing the wild type (WT) mice bred in the local facility (WT-INT) and the WT mice purchased from Jacksons (WT-EXT).

Author Contributions: Conceptualization, M.A.-M., A.P. and K.S.; methodology, M.A.-M., K.S., A.P.; validation, M.A.-M., K.S., A.P., S.Z. and Ø.S.; formal analysis, A.P., K.S., S.Z. and Ø.S.; investigation, A.P., K.S., S.Z. and N.S.; data curation, A.P. and K.S.; writing—original draft preparation, M.A.-M., O.P.O., A.P. and K.S.; writing一review and editing, M.A.-M., O.P.O., K.S., A.P., S.Z. and N.S.; visualization, A.P., K.S. and N.S.; supervision, M.A.-M.; project administration, M.A.-M.; funding acquisition, M.A.-M. All authors have read and agreed to the published version of the manuscript.

Funding: This research was funded by The Olav Thon Foundation, grant number 16-1606.

Acknowledgments: We are grateful to Bjørg Riber, Karen-Marie Gujord and Bashir Hakim for technical assistance. Finn-Mogens Haug for assistance with the analysis program, and Trygve Leergaard for assistance with the stereology program.

Conflicts of Interest: The authors declare no conflict of interest.

\section{References}

1. Nagelhus, E.A.; Ottersen, O.P. Physiological roles of Aquaporin-4 in brain. Physiol. Rev. 2013, 93, $1543-1562$. [CrossRef] [PubMed]

2. Mylonakou, M.N.; Petersen, P.H.; Rinvik, E.; Rojek, A.; Valdimarsdottir, E.; Zelenin, S.; Zeuthen, T.; Nielsen, S.; Ottersen, O.P.; Amiry-Moghaddam, M. Analysis of mice with targeted deletion of AQP9 gene provides conclusive evidence for expression of AQP9 in neurons. J. Neurosci. Res. 2009, 87, 1310-1322. [CrossRef] [PubMed]

3. Badaut, J.; Petit, J.-M.; Brunet, J.-F.; Magistretti, P.J.; Charriaut-Marlangue, C.; Regli, L. Distribution of Aquaporin 9 in the adult rat brain: Preferential expression in catecholaminergic neurons and in glial cells. Neuroscience 2004, 128, 27-38. [CrossRef] [PubMed] 
4. Badaut, J.; Lasbennes, F.; Magistretti, P.J.; Regli, L. Aquaporins in brain: Distribution, physiology, and pathophysiology. Br. J. Pharmacol. 2002, 22, 367-378. [CrossRef] [PubMed]

5. Nielsen, S.; Nagelhus, E.A.; Amiry-Moghaddam, M.; Bourque, C.; Agre, P.; Ottersen, O.P. Specialized membrane domains for water transport in glial cells: High-resolution immunogold cytochemistry of aquaporin-4 in rat brain. J. Neurosci. 1997, 17, 171-180. [CrossRef] [PubMed]

6. Amiry-Moghaddam, M.; Frydenlund, D.; Ottersen, O. Anchoring of aquaporin-4 in brain: Molecular mechanisms and implications for the physiology and pathophysiology of water transport. Neuroscience 2004, 129, 997-1008. [CrossRef] [PubMed]

7. Amiry-Moghaddam, M.; Ottersen, O.P. The molecular basis of water transport in the brain. Nat. Rev. Neurosci. 2003, 4, 991-1001. [CrossRef]

8. Stahl, K.; Rahmani, S.; Prydz, A.; Skauli, N.; Macaulay, N.; Mylonakou, M.N.; Torp, R.; Skare, O.; Berg, T.; Leergaard, T.B.; et al. Targeted deletion of the aquaglyceroporin AQP9 is protective in a mouse model of Parkinson's disease. PLoS ONE 2018, 13, e0194896. [CrossRef]

9. Carbrey, J.M.; Gorelick-Feldman, D.A.; Kozono, D.; Praetorius, J.; Nielsen, S.; Agre, P. Aquaglyceroporin AQP9: Solute permeation and metabolic control of expression in liver. Proc. Natl. Acad. Sci. USA 2003, 100, 2945-2950. [CrossRef]

10. Manley, G.T.; Fujimura, M.; Ma, T.; Noshita, N.; Filiz, F.; Bollen, A.W.; Chan, P.; Verkman, A. Aquaporin-4 deletion in mice reduces brain edema after acute water intoxication and ischemic stroke. Nat. Med. 2000, 6, 159-163. [CrossRef] [PubMed]

11. Vajda, Z.; Pedersen, M.; Füchtbauer, E.-M.; Wertz, K.; Stødkilde-Jørgensen, H.; Sulyok, E.; Dóczi, T.; Neely, J.D.; Agre, P.; Frokiaer, J.; et al. Delayed onset of brain edema and mislocalization of aquaporin-4 in dystrophin-null transgenic mice. Proc. Natl. Acad. Sci. USA 2002, 99, 13131-13136. [CrossRef] [PubMed]

12. Frydenlund, D.S.; Bhardwaj, A.; Otsuka, T.; Mylonakou, M.N.; Yasumura, T.; Davidson, K.G.V.; Zeynalov, E.; Skare, O.; Laake, P.; Haug, F.-M.; et al. Temporary loss of perivascular aquaporin-4 in neocortex after transient middle cerebral artery occlusion in mice. Proc. Natl. Acad. Sci. USA 2006, 103, 13532-13536. [CrossRef]

13. Hirt, L.; Ternon, A.; Price, M.; Mastour, N. Protective role of early aquaporin 4 induction against postischemic edema formation. Br. J. Pharmacol. 2008, 29, 423-433. [CrossRef]

14. Papadopoulos, M.C.; Verkman, A.S. Aquaporin water channels in the nervous system. Nat. Rev. Neurosci. 2013, 14, 265-277. [CrossRef] [PubMed]

15. Alvestad, S.; Hammer, J.; Hoddevik, E.H.; Skare, O.; Sonnewald, U.; Amiry-Moghaddam, M.; Ottersen, O.P. Mislocalization of AQP4 precedes chronic seizures in the kainate model of temporal lobe epilepsy. Epilepsy Res. 2013, 105, 30-41. [CrossRef] [PubMed]

16. Eid, T.; Lee, T.-S.W.; Thomas, M.J.; Amiry-Moghaddam, M.; Bjørnsen, L.P.; Spencer, D.D.; Agre, P.; Ottersen, O.P.; De Lanerolle, N.C. Loss of perivascular aquaporin 4 may underlie deficient water and K + homeostasis in the human epileptogenic hippocampus. Proc. Natl. Acad. Sci. USA 2005, 102, 1193-1198. [CrossRef]

17. Yang, J.; Lunde, L.L.; Paworn, N.; Tomohiro, O.; Camassa, L.M.A.; Nilsson, N.G.; Lannfelt, L.; Xu, Y.; Amiry-Moghaddam, M.; Ottersen, O.P.; et al. Loss of astrocyte polarization in the tg-ArcSwe mouse model of Alzheimer's disease. J. Alzheimers Dis. 2011, 27, 711-722. [CrossRef]

18. Pérez, E.; Barrachina, M.; Rodríguez, A.; Torrejón-Escribano, B.; Boada, M.; Hernández, I.; Sánchez, M.; Ferrer, I. Aquaporin expression in the cerebral cortex is increased at early stages of Alzheimer disease. Brain Res. 2007, 1128, 164-174. [CrossRef]

19. Moftakhar, P.; Lynch, M.D.; Pomakian, J.L.; Vinters, H.V. Aquaporin expression in the brains of patients with or without cerebral amyloid angiopathy. J. Neuropathol. Exp. Neurol. 2010, 69, 1201-1209. [CrossRef]

20. Hoshi, A.; Yamamoto, T.; Shimizu, K.; Ugawa, Y.; Nishizawa, M.; Takahashi, H.; Kakita, A. Characteristics of aquaporin expression surrounding senile plaques and cerebral amyloid angiopathy in Alzheimer disease. J. Neuropathol. Exp. Neurol. 2012, 71, 750-759. [CrossRef]

21. Kaiser, M.; Maletzki, I.; Hülsmann, S.; Holtmann, B.; Schulz-Schaeffer, W.; Kirchhoff, F.; Bähr, M.; Neusch, C. Progressive loss of a glial potassium channel (KCNJ10) in the spinal cord of the SOD1 (G93A) transgenic mouse model of amyotrophic lateral sclerosis. J. Neurochem. 2006, 99, 900-912. [CrossRef]

22. Nicaise, C.; Soyfoo, M.S.; Authelet, M.; De Decker, R.; Bataveljić, D.; Delporte, C.; Roland, P. Aquaporin-4 overexpression in rat ALS model. Anat. Rec. Adv. Integr. Anat. Evol. Biol. 2009, 292, 207-213. [CrossRef] 
23. Wu, T.-T.; Su, F.-J.; Feng, Y.-Q.; Liu, B.; Li, M.-Y.; Liang, F.-Y.; Li, G.; Li, X.-J.; Zhang, Y.; Cai, Z.-Q.; et al. Mesenchymal stem cells alleviate AQP-4-dependent glymphatic dysfunction and improve brain distribution of antisense oligonucleotides in BACHD mice. STEM CELLS 2019. [CrossRef]

24. Costa, C.; Tortosa, R.; Rodriguez, A.; Ferrer, I.; Torres, J.M.; Bassols, A.; Pumarola, M.B. Aquaporin 1 and aquaporin 4 overexpression in bovine spongiform encephalopathy in a transgenic murine model and in cattle field cases. Brain Res. 2007, 1175, 96-106. [CrossRef]

25. Papadopoulos, M.C.; Verkman, A.S. Aquaporin-4 gene disruption in mice reduces brain swelling and mortality in pneumococcal meningitis. J. Biol. Chem. 2005, 280, 13906-13912. [CrossRef] [PubMed]

26. Promeneur, D.; Lunde, L.K.; Amiry-Moghaddam, M.; Agre, P. Protective role of brain water channel AQP4 in murine cerebral malaria. Proc. Natl. Acad. Sci. USA 2012, 110, 1035-1040. [CrossRef]

27. Lennon, V.A.; Kryzer, T.J.; Pittock, S.J.; Verkman, A.S.; Hinson, S.R. IgG marker of optic-spinal multiple sclerosis binds to the aquaporin-4 water channel. J. Exp. Med. 2005, 202, 473-477. [CrossRef] [PubMed]

28. Gershen, L.D.; Zanotti-Fregonara, P.; Dustin, I.H.; Liow, J.-S.; Hirvonen, J.; Kreisl, W.C.; Jenko, K.J.; Inati, S.K.; Fujita, M.; Morse, C.L.; et al. Neuroinflammation in temporal lobe epilepsy measured using positron emission tomographic imaging of translocator protein. JAMA Neurol. 2015, 72, 882-888. [CrossRef] [PubMed]

29. Amor, S.; Puentes, F.; Baker, D.; Van Der Valk, P. Inflammation in neurodegenerative diseases. Immunology 2010, 129, 154-169. [CrossRef]

30. Troncoso-Escudero, P.; Parra, A.; Nassif, M.; Vidal, R.L. Outside in: Unraveling the role of neuroinflammation in the progression of Parkinson's disease. Front. Neurol. 2018, 9, 860. [CrossRef]

31. Li, L.; Zhang, H.; Varrin-Doyer, M.; Zamvil, S.S.; Verkman, A.S. Proinflammatory role of aquaporin-4 in autoimmune neuroinflammation. FASEB J. 2011, 25, 1556-1566. [CrossRef]

32. Martinez, F.O.; Gordon, S. The M1 and M2 paradigm of macrophage activation: Time for reassessment. F1000Prime Rep. 2014, 6, 13. [CrossRef]

33. Nau, G.J.; Richmond, J.F.L.; Schlesinger, A.; Jennings, E.G.; Lander, E.S.; Young, R.A. Human macrophage activation programs induced by bacterial pathogens. Proc. Natl. Acad. Sci. USA 2002, 99, 1503-1508. [CrossRef]

34. Prydz, A.; Stahl, K.; Puchades, M.; Davarpaneh, N.; Nadeem, M.; Ottersen, O.P.; Gundersen, V.; Amiry-Moghaddam, M. Subcellular expression of aquaporin-4 in substantia nigra of normal and MPTP-treated mice. Neuroscience 2017, 359, 258-266. [CrossRef]

35. Dauer, W.; Przedborski, S. Parkinson's disease: Mechanisms and models. Neuron 2003, 39, 889-909. [CrossRef]

36. Ofori, E.; Pasternak, O.; Planetta, P.J.; Burciu, R.; Snyder, A.; Febo, M.; Golde, T.E.; Okun, M.S.; Vaillancourt, D.E. Increased free water in the substantia nigra of Parkinson's disease: A single-site and multi-site study. Neurobiol. Aging 2015, 36, 1097-1104. [CrossRef]

37. Thrane, A.S.; Rappold, P.M.; Fujita, T.; Torres, A.; Bekar, L.K.; Takano, T.; Peng, W.; Wang, F.; Thrane, V.R.; Enger, R.; et al. Critical role of aquaporin-4 (AQP4) in astrocytic $\mathrm{Ca}_{2}+$ signaling events elicited by cerebral edema. Proc. Natl. Acad. Sci. USA 2011, 108, 846-851. [CrossRef]

38. Paxinos, G.A.F.K. The Mouse Brain in Sterotaxic Coordinates, 3rd ed.; Elsevier Inc.: San Diego, CA, USA, 2007.

39. Van Lookeren Campagne, M.; Oestreicher, A.B.; Buma, P.; Verkleij, A.J.; Gispen, W.H. Ultrastructural localization of adrenocorticotrophic hormone and the phosphoprotein B-50/growth-associated protein 43 in freeze-substituted, Lowicryl HM20-embedded mesencephalic central gray substance of the rat. Neuroscience 1991, 42, 517-529. [CrossRef]

40. Amiry-Moghaddam, M.; Lindland, H.; Zelenin, S.; Roberg, B.Å.; Gundersen, B.B.; Petersen, P.; Rinvik, E.; Torgner, I.A.; Ottersen, O.P. Brain mitochondria contain aquaporin water channels: Evidence for the expression of a short AQP9 isoform in the inner mitochondrial membrane. FASEB J. 2005, 19, 1459-1467. [CrossRef]

41. Wu, D.C.; Jackson-Lewis, V.; Vila, M.; Tieu, K.; Teismann, P.; Vadseth, C.; Choi, D.-K.; Ischiropoulos, H.; Przedborski, S. Blockade of microglial activation is neuroprotective in the 1-Methyl-4-Phenyl-1,2,3,6tetrahydropyridine mouse model of Parkinson disease. J. Neurosci. 2002, 22, 1763-1771. [CrossRef]

42. Davis, E.; Foster, T.; Thomas, W. Cellular forms and functions of brain microglia. Brain Res. Bull. 1994, 34, 73-78. [CrossRef]

43. Janova, H.; Böttcher, C.; Holtman, I.R.; Regen, T.; Van Rossum, D.; Götz, A.; Ernst, A.-S.; Fritsche, C.; Gertig, U.; Saiepour, N.; et al. CD14 is a key organizer of microglial responses to CNS infection and injury. Glia 2015, 64, 635-649. [CrossRef] 
44. Cignarella, F.; Filipello, F.; Bollman, B.; Cantoni, C.; Locca, A.; Mikesell, R.; Manis, M.; Ibrahim, A.; Deng, L.; Benitez, B.A.; et al. TREM2 activation on microglia promotes myelin debris clearance and remyelination in a model of multiple sclerosis. Acta Neuropathol. 2020, 140, 513-534. [CrossRef]

45. Chen, G.; Zhou, Z.; Sha, W.; Wang, L.; Yan, F.; Yang, X.; Qin, X.; Wu, M.; Li, D.; Tian, S.; et al. A novel CX3CR1 inhibitor AZD8797 facilitates early recovery of rat acute spinal cord injury by inhibiting inflammation and apoptosis. Int. J. Mol. Med. 2020, 45, 1373-1384. [CrossRef]

46. Ewolf, Y.; Eyona, S.; Ekim, K.-W.; Jung, S. Microglia, seen from the CX3CR1 angle. Front. Cell. Neurosci. 2013, 7, 26. [CrossRef]

47. Jeetle, J.K.; Hagger, G.N.; Topps, S.S.; Male, D.; Rezaie, P. Microglial colonization of the developing mouse brain: The effect of CD11b deletion. Neuropathol. Appl. Neurobiol. 2002, 28, 164. [CrossRef]

48. Kalkonde, Y.V.; Morgan, W.W.; Sigala, J.; Maffi, S.K.; Condello, C.; Kuziel, W.; Ahuja, S.S.; Ahuja, S.K. Chemokines in the MPTP model of Parkinson's disease: Absence of CCL2 and its receptor CCR2 does not protect against striatal neurodegeneration. Brain Res. 2007, 1128, 1-11. [CrossRef]

49. Xue, X.; Zhang, W.; Zhu, J.; Chen, X.; Zhou, S.; Xu, Z.; Hu, G.; Su, C. Aquaporin-4 deficiency reduces TGF- $\beta 1$ in mouse midbrains and exacerbates pathology in experimental Parkinson's disease. J. Cell. Mol. Med. 2019, 23, 2568-2582. [CrossRef] [PubMed]

50. Lehrmann, E.; Kiefer, R.; Finsen, B.; Diemer, N.H.; Zimmer, J.; Hartung, H.P. Cytokines in cerebral ischemia: Expression of transforming growth factor beta-1 (TGF- $\beta 1$ ) mRNA in the postischemic adult rat hippocampus. Exp. Neurol. 1995, 131, 114-123. [CrossRef]

51. Spittau, B. Transforming growth factor $\beta 1$-mediated anti-inflammation slows progression of midbrain dopaminergic neurodegeneration in Parkinson's disease? Neural Regen. Res. 2015, 10, 1578-1580. [CrossRef]

52. Chen, S.; Luo, D.; Streit, W.J.; Harrison, J.K. TGF-beta1 upregulates CX3CR1 expression and inhibits fractalkine-stimulated signaling in rat microglia. J. Neuroimmunol. 2002, 133, 46-55. [CrossRef]

53. Farina, C.; Aloisi, F.; Meinl, E. Astrocytes are active players in cerebral innate immunity. Trends Immunol. 2007, 28, 138-145. [CrossRef]

54. Guedes, J.R.; Lao, T.; Cardoso, A.L.; El Khoury, J. Roles of microglial and monocyte chemokines and their receptors in regulating Alzheimer's disease-associated amyloid- $\beta$ and Tau pathologies. Front. Neurol. 2018, 9, 549. [CrossRef]

55. Clarner, T.G.; Janssen, K.; Nellessen, L.; Stangel, M.; Skripuletz, T.; Krauspe, B.; Hess, F.-M.; Denecke, B.; Beutner, C.; Linnartz-Gerlach, B.; et al. CXCL10 triggers early microglial activation in the cuprizone model. J. Immunol. 2015, 194, 3400-3413. [CrossRef]

56. Dong, Y.; Yuan, Y.; Fang, Y.; Zheng, T.; Du, D.; Gao, D.; Du, J.; Liu, L.; He, Q. Effect of aquaporin 4 protein overexpression in nigrostriatal system on development of Parkinson's disease. Int. J. Neurosci. 2020, 1-8. [CrossRef]

57. Tourdias, T.; Mori, N.; Dragonu, I.; Cassagno, N.; Boiziau, C.; Aussudre, J.; Brochet, B.; Moonen, C.T.; Klaus, P.; Dousset, V. Differential aquaporin 4 expression during edema build-up and resolution phases of brain inflammation. J. Neuroinflamm. 2011, 8, 143. [CrossRef]

58. Edwards, J.P.; Zhang, X.; Frauwirth, K.A.; Mosser, D.M. Biochemical and functional characterization of three activated macrophage populations. J. Leukoc. Biol. 2006, 80, 1298-1307. [CrossRef]

59. Vivekanantham, S.; Shah, S.; Dewji, R.; Dewji, A.; Khatri, C.; Ologunde, R. Neuroinflammation in Parkinson's disease: Role in neurodegeneration and tissue repair. Int. J. Neurosci. 2015, 125, 717-725. [CrossRef]

60. Lee, H.-J.; Suk, J.-E.; Patrick, C.; Bae, E.-J.; Cho, J.-H.; Rho, S.; Hwang, D.; Masliah, E.; Lee, S.-J. Direct transfer of $\alpha$-synuclein from neuron to astroglia causes inflammatory responses in synucleinopathies. J. Biol. Chem. 2010, 285, 9262-9272. [CrossRef]

61. Hammond, S.L.; Bantle, C.M.; Popichak, K.A.; Wright, K.A.; Thompson, D.; Forero, C.; Kirkley, K.S.; Damale, P.U.; Chong, E.K.P.; Tjalkens, R.B. NF-кB signaling in astrocytes modulates brain inflammation and neuronal injury following sequential exposure to manganese and MPTP during development and Aging. Toxicol. Sci. 2020, 177, 506-520. [CrossRef]

62. Zhang, J.; Yang, B.; Sun, H.; Zhou, Y.; Liu, M.; Ding, J.; Fang, F.; Fan, Y.; Hu, G. Aquaporin-4 deficiency diminishes the differential degeneration of midbrain dopaminergic neurons in experimental Parkinson's disease. Neurosci. Lett. 2016, 614, 7-15. [CrossRef]

63. Liang, R.; Yong, S.; Huang, X.; Kong, H.; Hu, G.; Fan, Y. Aquaporin-4 mediates the suppressive effect of Lipopolysaccharide on hippocampal neurogenesis. Neuroimmunomodulation 2016, 23, 309-317. [CrossRef] 
64. Zhou, J.; Kong, H.; Hua, X.; Xiao, M.; Ding, J.; Hu, G. Altered blood-brain barrier integrity in adult aquaporin-4 knockout mice. NeuroReport 2008, 19, 1-5. [CrossRef]

65. Eilert-Olsen, M.; Haj-Yasein, N.N.; Vindedal, G.F.; Enger, R.; Gundersen, G.A.; Hoddevik, E.H.; Petersen, P.H.; Haug, F.-M.S.; Skare, O.; Adams, M.E.; et al. Deletion of aquaporin-4 changes the perivascular glial protein scaffold without disrupting the brain endothelial barrier. Glia 2011, 60, 432-440. [CrossRef]

66. García-Domínguez, I.; Veselá, K.; García-Revilla, J.; Carrillo-Jiménez, A.; Roca-Ceballos, M.A.; Santiago, M.; De Pablos, R.M.; Venero, J.L. Peripheral inflammation enhances microglia response and nigral dopaminergic cell death in an in vivo MPTP model of Parkinson's disease. Front. Cell. Neurosci. 2018, 12, 398. [CrossRef]

67. Koizumi, S.; Shigemoto-Mogami, Y.; Nasu-Tada, K.; Shinozaki, Y.; Ohsawa, K.; Tsuda, M.; Joshi, B.V.; Jacobson, K.A.; Kohsaka, S.; Inoue, K. UDP acting at P2Y6 receptors is a mediator of microglial phagocytosis. Nat. Cell Biol. 2007, 446, 1091-1095. [CrossRef]

68. Pizzoni, A.; Bazzi, Z.; Di Giusto, G.; Alvarez, C.L.; Rivarola, V.; Capurro, C.; Schwarzbaum, P.J.; Ford, P. Release of ATP by TRPV4 activation is dependent upon the expression of AQP2 in renal cells. J. Cell. Physiol. 2020. [CrossRef] [PubMed]

69. Benfenati, V.; Caprini, M.; Dovizio, M.; Mylonakou, M.N.; Ferroni, S.; Ottersen, O.P.; Amiry-Moghaddam, M. An aquaporin-4/transient receptor potential vanilloid 4 (AQP4/TRPV4) complex is essential for cell-volume control in astrocytes. Proc. Natl. Acad. Sci. USA 2011, 108, 2563-2568. [CrossRef]

70. Meshorer, E.; Biton, I.E.; Ben-Shaul, Y.; Ben-Ari, S.; Assaf, Y.; Soreq, H.; Cohen, Y. Chronic cholinergic imbalances promote brain diffusion and transport abnormalities. FASEB J. 2005, 19, 910-922. [CrossRef]

71. Gupta, M.; Gupta, B.; Thomas, R.; Bruemmer, V.; Sladek, J.; Felten, D. Aged mice are more sensitive to 1-methyl-4-phenyl-1,2,3,6-tetrahydropyridine treatment than young adults. Neurosci. Lett. 1986, 70, 326-331. [CrossRef]

72. Gupta, R.; Kanungo, M. Glial molecular alterations with mouse brain development and aging: Up-regulation of the Kir4.1 and aquaporin-4. AGE 2011, 35, 59-67. [CrossRef] [PubMed]

73. Noelker, C.; Morel, L.; Lescot, T.; Osterloh, A.; Alvarez-Fischer, D.; Breloer, M.; Henze, C.; Depboylu, C.; Skrzydelski, D.; Michel, P.P.; et al. Toll like receptor 4 mediates cell death in a mouse MPTP model of Parkinson disease. Sci. Rep. 2013, 3, 1393. [CrossRef]

74. Fiebich, B.L.; Batista, C.R.A.; Saliba, S.W.; Yousif, N.M.; De Oliveira, A.C.P. Role of microglia TLRs in neurodegeneration. Front. Cell. Neurosci. 2018, 12, 329. [CrossRef]

75. Mogi, M.; Harada, M.; Kondo, T.; Riederer, P.; Inagaki, H.; Minami, M.; Nagatsu, T. Interleukin-1 beta, interleukin-6, epidermal growth factor and transforming growth factor-alpha are elevated in the brain from parkinsonian patients. Neurosci. Lett. 1994, 180, 147-150. [CrossRef]

76. McGeer, P.L.; Kawamata, T.; Walker, D.G.; Akiyama, H.; Tooyama, I.; McGeer, E.G. Microglia in degenerative neurological disease. Glia 1993, 7, 84-92. [CrossRef]

Publisher's Note: MDPI stays neutral with regard to jurisdictional claims in published maps and institutional affiliations.

(C) 2020 by the authors. Licensee MDPI, Basel, Switzerland. This article is an open access article distributed under the terms and conditions of the Creative Commons Attribution (CC BY) license (http://creativecommons.org/licenses/by/4.0/). 